\title{
Prototype alat monitoring lingkungan sekolah berbasis Raspberry bagi siswa dan guru SMK Negeri 5 Kabupaten Gowa
}

\author{
Yunus Tjandi ${ }^{1}$, Zulhaji $^{2}$ \\ ${ }^{1,2}$ Fakultas Teknik, Universitas Negeri Makassar
}

\begin{abstract}
Improper installation and not in accordance with PUIL standards of Monitoring device, will provide a detriment for consumers of electricity. The objectives to be achieved in the Community Partnership Program (PKM) are: (1) to increase the knowledge of Teachers and Students of Gowa 5 Vocational School (partners) to monitor and control the electrical equipment of the School Environment and electrical equipment using Smartphone/Computer, (2) To improve the skills of Teachers and Students of Gowa 5 Vocational School (partners) in making and utilizing the Raspberry-based Monitoring and Control system, (3) improving the skills of Teachers and Students of the National Vocational School and Somba Opu SMKT in making interface and application system based on Arduino Mega to monitor and control electrical equipment device of a house/building. The methods used of this Workshop are the lecture method, discussion, and demonstration. The results of this PKM are (1) Increasing Partner Knowledge in making Arduino Mega-based monitoring and control software, (2) Increasing Partner Skills in terms of making and utilizing Arduino Mega-based Monitoring and Control System for monitoring and controlling electricity devices of a house/building, (3) increasing Skill and knowledge of Partners in order to be able to provide easy solutions at Gowa 5 Vocational School, in monitoring and controlling electrical devices in the School environment, so that the tools can be controlled using smartphone, both from a close range or remotely. The method used in giving the material is the lecture method, and discussion while the application uses the demonstration method. The results of the Community Partnership Program (PKM) illustrate that the group of Teachers and Students of Gowa 5 Vocational School (partners) have: (1) possessed knowledge in making Raspberry-based Monitoring and Control device to monitor School Environments and electrical equipment using Smartphone/Computer, (2) have skills in making and utilizing Raspberry-based Monitoring and Control device, (3) having skills and knowledge to be able to provide easy solutions for Gowa 5 Vocational School.
\end{abstract}

Keywords: monitoring and control device, electrical device, Raspberry, smartphone

\section{PENDAHULUAN}

Sebagian besar kegiatan manusia saat ini bergantung pada listrik, baik yang sifatnya primer maupun sekunder. Listrik juga sangat penting dalam kehidupan pribadi, sosial, pendidikan, dan perdagangan. Dapat dibayangkan apabila rumah/ bangunan ditinggalkan lama oleh pemiliknya, dan lupa memadamkan perangkat peralatan listriknya, tentu pemilik rumah tidak tenang dan selalu waswas serta gelisah. Dengan adanya sistem kendali yang akan dibuat dalam Workshop oleh Mitra (Guru dan Siswa SMK Nasional dan SMKT Somba Opu Kabupaten Gowa)ini, pemilik rumah/ bangunan tidak perlu khawatir, karena perangkat peralatan listriknya dapat dikendalikan dari jarak jauh (dengan menggunakan smartphone) sehingga memperkecil timbulnya kebakaran atau hal-hal yang tidak diinginkan (Tjandi, 2016).

Saat ini telah banyak teknologi baru yang diciptakan, salah satu yang akan diworkshopkan dan dilatihkan oleh pengabdi adalah Alat Monitoring dan Kendali perangkat peralatan listrik berbasis Raspberry yang dapat memonitor dan mengendalikan Lingkungan Sekolah dan perangkat listriknya baik dari jarak jauh, maupun dari jarak dekat dengan menggunakan Smartphone. SMK Negeri 5 Kabupaten Gowa sebagai sekolah kejuruan yang ada di Kabupaten Gowa dengan beberapa jurusannya antara lain adalah Teknik Kendali Listrik dan Jaringan Komputer, seharusnya sudah dapat membuat berbagai jenis alat kendali di Sekolahnya, namun permasalahan yang dihadapi adalah hal tersebut belum dapat dirasakan karena biaya untuk membeli alat-alat pendukung 
perangkat monitor dan kendali, seperti Raspberry, Relay Bord, Smartphone dan lain-lain belum disediakan oleh pihak sekolah, disamping pengetahuan mitra masih terbatas tentang hal yang dibahas.

Pembuatan Perangkat Alat Monitor dan Kendali berbasis Raspberry di lingkungan SMK Negeri 5 Kabupaten Gowa belum pernah dilakukan. Berdasarkan analisis situasi terhadap kemungkinan upaya pelaksanaan workshop pembuatan Alat Monitoring dan Kendali berbasis Raspberry sebagai media untuk memperluas wawasan pengetahuan Teknologi dibidang Kendali diyakini sangat besar peluangnya.

\section{PERMASAlahan Mitra}

1. Bagaimana meningkatkan pengetahuan Guru dan Siswa SMK Negeri 5 Kabupaten Gowa dalam pembuatan Software sistem monitoring dan kendali berbasis Raspberry untuk memonitoring dan mengendalikan perangkat peralatan listrik di Sekolahnya?

2. Bagaimana meningkatkan keterampilan SMK Negeri 5 Kabupaten Gowa dalam pembuatan dan pemanfaatan Alat Monitoring dan Kendali berbasis Raspberry untuk memonitoring dan mengendalikan perangkat peralatan listrik di Sekolahnya?

3. Bagaimana meningkatkan keterampilan Guru dan Siswa SMK Negeri 5 Kabupaten Gowa dalam pembuatan interface dan aplikasi sistem kendali berbasis Raspberry untuk memonitor dan mengendalikan perangkat peralatan listrik di Sekolahnya?

4. Bagaimana meningkatkan Skil dan pengetahuan Mitra agar mampu memberikan solusi mudah bagi permasalahan yang dihadapi di SMK Negeri 5 Kabupaten Gowa?

\section{SOLUSI YANG DITAWARKAN}

\section{A. Metode Pendekatan yang Ditawarkan}

1. Workshop dan pelatihan pembuatan Alat Monitoring dan Kendali berbasis Raspberry bagi Guru dan Siswa SMK Negeri 5 Kabupaten
Gowa yang bisa memonitoring dan mengendalikan perangkat peralatan listrik suatu Sekolah/ Gedung.

2. Mengimplementasikan sistem monitoring dan kendali berbasis Raspberry ini pada lokasi Mitra sebagai solusi hemat bagi permasalahan mitra.

3. Mendorong lahirnya technopreneurship yang kreatif yang bisa membuat alat monitoring dan kendali berbasis Raspberry untuk dipasarkan guna terciptanya masyarakat IT (dalam sistem kendali) di negara kita.

\section{B. Rencana Kegiatan}

Kegiatan pengabdian kepada masyarakat ini, dilaksanakan dengan menggunakan beberapa metode, yaitu:

1. Metode Ceramah; Metode ini digunakan pada waktu penyajian materi dalam bentuk pengetahuan dan pemahaman teoritis tentang perangkat lunak dan perangkat keras sistem kendali yang digunakan.

2. Metode Diskusi dan Tanya jawab; Metode ini digunakan untuk mengetahui pengetahuan mitra secara umum dan memotivasi mitra tentang pentingnya pengetahuan Alat Monitoring dan Kendali berbasis Raspberry bagi Guru-guru dan siswa.

3. Metode Demonstrasi; Metode ini digunakan untuk memberikan tips dan trik mudah dalam merakit, mengoperasikan dan memanfaatkan perangkat Monitoring dan kendali berbasis Raspberry.

4. Interaksi langsung yang dikemas dalam bentuk workshop sehingga tidak hanya terbatas pada teori tetapi langsung pada praktek penggunaannya secara langsung.

5. Metode Evaluasi; Metode ini digunakan untuk mengukur daya serap peserta terhadap materi yang telah diajarkan. 


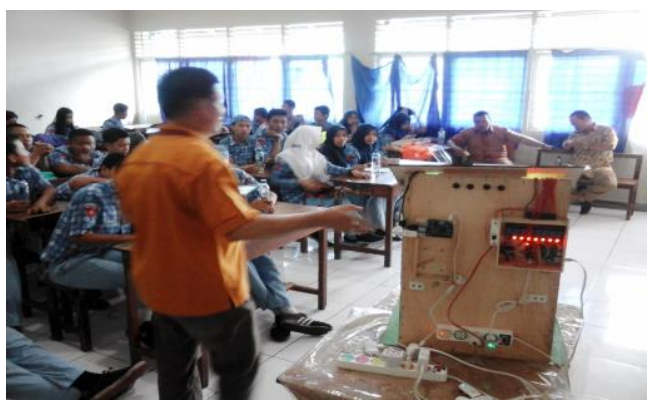

Gambar 1. Petunjuk penggunaan Raspberry

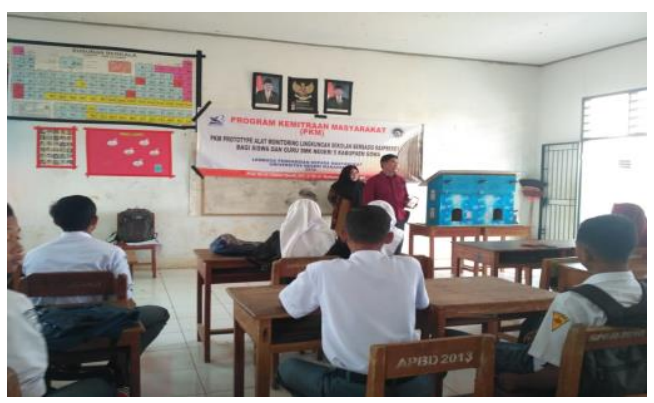

Gambar 2. Petunjuk yang diberikan oleh Pembimbing

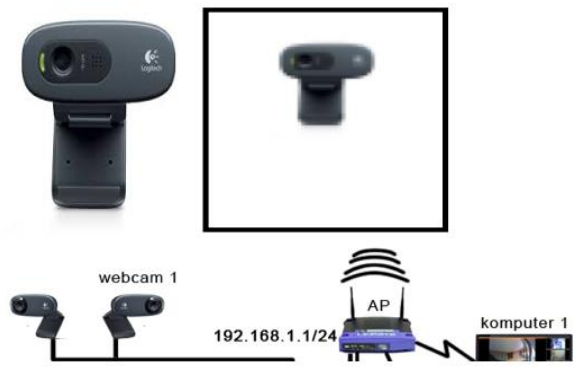

Gambar 3. Alat monitor yang akan dirakit oleh siswa

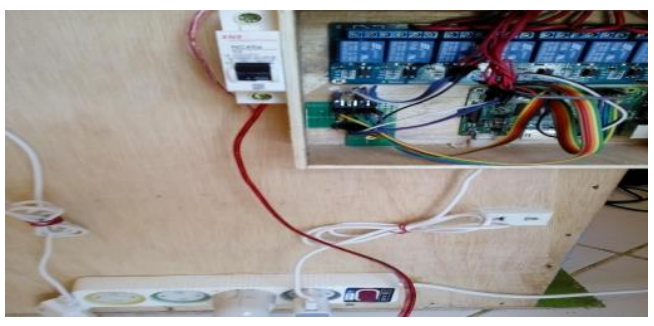

Gambar 4. Pengaman dan Relay Board

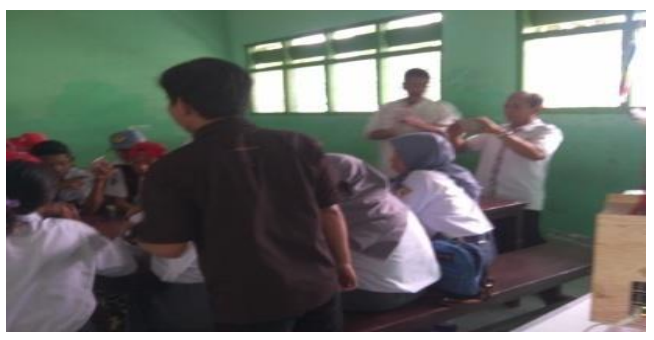

Gambar 5. Pelatihan pembuatan alat monitor

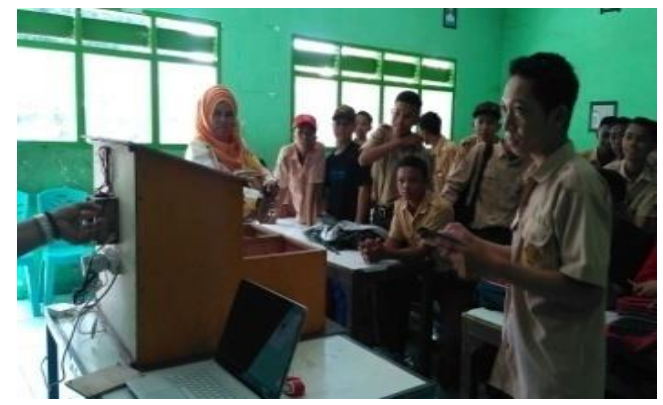

Gambar 6. Persiapan alat monitor oleh Siswa

C. Proses Pengoperasian Alat Monitoring dan Kendali berbasis Raspberry

1. Mempersiapkan alat dan bahan.

2. Mengaktifkan Smartphone dengan IP Adress

3. Mengaktifkan semua perangkat Kendali; Access point, Raspberry, Relay Board, Webcam dan perangkat-perangkat pendukung kecil.

4. Sistem Pengaman (MCB) dapat langsung dikendalikan melalui Smartphone, dengan menekan tombol ON, maka MCB dapat langsung berfungsi untuk mengamankan semua perangkat peralatan listrik yang ada pada Sekolah/gedung (pada Board House), sebaliknya apabila kita menekan tombol OFF maka semua perangkat peralatan listrik yang ada di dalam rumah/kantor (Board House) akan padam semua karena pengaman MCB berfungsi dengan sangat baik.

5. Dengan menekan Tombol ON pada posisi Saklar di Smartphone, maka lampu-lampu listrik akan menyala, sesuai dengan posisi masing-masing saklar yang terdapat di dalam Board House tersebut. Lampu-lampu listrik ini dapat dikendalikan secara manual biasa, yaitu dengan menggunakan saklar Push ON atau dengan menggunakan kendali melalui jaringan internet. Demikian juga untuk memadamkan peralatan listrik tersebut dapat dilakukan melalui tombol Smartphone dan dapat juga secara manual melalui tombol saklar yang terpasang.

6. Dengan menekan Tombol ON pada posisi $\mathrm{KKB}$, maka KKB tersebut atau TV yang dipasang pada KKB tersebut akan berfungsi/ menyala, dan sebaliknya apabila posisi tombol 
OFF ditekan, maka perangkat alat tersebut akan padam.

7. Semua Peralatan Listrik tersebut dapat dikendalikan baik dari jarak Dekat, maupun dari jarak Jauh, dengan menggunakan jaringan Internet melalui Smartphone.

\section{KESIMPULAN}

Berdasarkan kegiatan Workshop dan pelatihan yang dilakukan di lokasi PKM, maka dapat disimpulkan sebagai berikut:

1. Kelompok Guru dan Siswa SMK Negeri 5 Kabupaten Gowa (Mitra) mengetahui tentang pentingnya Alat Monitoring dan Kendali berbasis Raspberry untuk memonitoring dan mengendalikan peralatan listrik pada Sekolah/ Gedung yang praktis, aman dan hemat energi.

2. Kelompok Guru dan Siswa SMK Negeri 5 Kabupaten Gowa (Mitra) terampil menyediakan alat dan bahan dalam pembuatan Alat Monitoring dan Kendali berbasis Raspberry.

3. Kelompok Guru dan Siswa SMK Negeri 5 Kabupaten Gowa (Mitra) terampil menghubungkan perangkat kendali dengan jaringan Internet melalui Modem Router TP-Link sehingga dapat berfungsi untuk mengontrol perangkat listrik dari jarak jauh.
4. Kelompok Guru dan Siswa SMK Negeri 5 Kabupaten Gowa (Mitra) mengetahui dan terampil merakit Alat Monitoring dan Kendali berbasis Raspberry.

5. Kelompok Guru dan Siswa SMK Negeri 5 Kabupaten Gowa (Mitra) mengetahui dan terampil merakit Alat Monitoring dan Kendali berbasis Raspberry yang dapat mengendalikan peralatan listrik pada Sekolah/Gedung baik dari jarak dekat, maupun dari jarak jauh secara praktis, aman dan hemat energi.

6. Lahirnya technopreneurship yang kreatif yang bisa membuat Alat Monitoring dan Kendali berbasis Raspberry yang dapat mengendalikan peralatan listrik pada Sekolah/gedung untuk dipasarkan guna terciptanya masyarakat IT (dalam perangkat alat kendali listrik) di lingkungan kita.

\section{DAFTAR PUSTAKA}

Tjandi, Y. 2016. Monitoring dan Kendali Perangkat Peralatan Listrik Berbasis Arduino Mega Menggunakan Smartphone. Lembaga Penelitian Universitas Negeri Makassar. 